\title{
Paramédicos en tiempos de pandemia. Historias de angustia, miedo y esperanza
}

\section{Paramedics in times of pandemic. Stories of anguish, fear and hope}

Paramédicos em tempos de pandemia. Histórias de angústia, medo e esperança

Germán Alejandro García Lara

Universidad de Ciencias y Artes de Chiapas, México

german.garcia@unicach.mx https://orcid.org/0000-0002-4075-4988

Irma Hernández Solís

Universidad de Ciencias y Artes de Chiapas, México irma.hernandez@unicach.mx https://orcid.org/0000-0001-7335-7519

Soledad Hernández Solís

Universidad de Ciencias y Artes de Chiapas, México soledad.hernandez@unicach.mx https://orcid.org/0000-0001-5621-986X

Oscar Cruz Pérez

Universidad de Ciencias y Artes de Chiapas, México oscar.cruz@unicach.mx https://orcid.org/0000-0003-2452-2834

Jesús Ocaña Zúñiga Universidad de Ciencias y Artes de Chiapas, México jesus.ocana@unicach.mx https://orcid.org/0000-0003-0300-0797 
Revista Iberoamericana

de las Ciencias Sociales y

Humanísticas

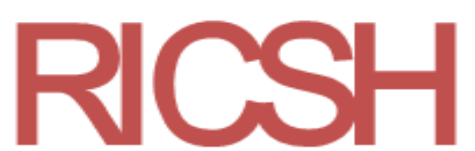

ISSN: $2395-7972$

\section{Resumen}

La emergencia sanitaria por covid-19 constituye un hecho social que cuestiona a la civilización en su conjunto; es un llamado de atención al tipo de vida y sociedad que desarrollamos. En el marco de esta pandemia, el presente trabajo analiza las vivencias de un grupo de paramédicos de la Cruz Roja Mexicana en torno a la labor que realizan en Tuxtla Gutiérrez, Chiapas, México. El estudio fue de tipo cualitativo, desarrollado a través del método interpretativo. Se aplicaron entrevistas semiestructuradas a tres paramédicos; los datos recopilados fueron examinados mediante la técnica de análisis de contenido, cuyos resultados exponen tres bloques temáticos: El amor a la camiseta en la Cruz Roja, donde se caracterizaron las actividades que realizan y el sentido de su tarea como voluntario; Tiempo de pandemia, 2020 describe el protocolo de atención a pacientes covid-19 y los sentimientos y temores que moviliza esta tarea, y ¿Quieres a la Cruz Roja o a tu familia? Perspectivas a partir de la covid-19, donde se reflexiona sobre la afectación a la salud en ellos mismos y su familia, su continuidad o no en la institución y la perspectiva de vida a partir del padecimiento de la enfermedad. El compromiso de apoyo y solidaridad como paramédico se ve profundamente conflictuado debido a la emergencia sanitaria, en que los límites que bordean la trama de dar al otro se quebrantan ante el sentimiento de vulnerabilidad y desamparo, en el miedo a contagiarse y contagiar a la familia y en el encuentro con la muerte, aspectos útiles para los servicios de contención y apoyo que deben ofrecerse a estos profesionales.

Palabra clave: angustia, covid-19, miedo, paramédicos.

\section{Abstract}

Covid-19's, health emergency is a total social event that questions civilization as a whole, is a call to the type of life and society that we develop. In the context of this pandemic, this paper analyzes the experiences of a group of paramedics from the Mexican Red Cross, around their work in Tuxtla Gutiérrez, Chiapas, Mexico. The study is of a qualitative type, developed through the interpretative method. Semi-structured interviews were applied to three paramedics, the data collected were examined using the content analysis technique, whose results expose three thematic blocks: Love of the t-shirt, in the Red Cross, where the activities they carry out and the sense of their work as a volunteer were characterized; Pandemic time, 2020, it describes the Covid-19 patients care protocol and the feelings and 


\section{Revista Iberoamericana \\ de las Ciencias Sociales y Humanísticas}

ISSN: $2395-7972$

fears that mobilize this task; and: Do you want the Red Cross or your family? Perspectives from Covid-19; reflecting on health affectation, in themselves and their family, their continuity or not in the institution and the perspective of life from the suffering of the disease. The commitment to support and solidarity as a paramedic is deeply conflicted by the health emergency, in which the boundaries bordering the plot of giving to the other are broken to the feeling of vulnerability and helplessness, in the fear of becoming infected and infecting the family and in the encounter with death, useful aspects for containment and support services that must be offered to these professionals.

Keywords: Anguish, Covid-19, fear, paramedics.

\section{Resumo}

A emergência sanitária decorrente do covid-19 constitui um fato social que questiona a civilização como um todo; É um chamado à atenção para o tipo de vida e sociedade que desenvolvemos. No contexto desta pandemia, este artigo analisa as experiências de um grupo de paramédicos da Cruz Vermelha mexicana com relação ao trabalho que realizam em Tuxtla Gutiérrez, Chiapas, México. O estudo foi qualitativo, desenvolvido por meio do método interpretativo. Entrevistas semiestruturadas foram aplicadas a três paramédicos; Os dados coletados foram examinados por meio da técnica de análise de conteúdo, cujos resultados mostram três blocos temáticos: O amor da camiseta na Cruz Vermelha, onde foram caracterizados as atividades que realizam e o significado do seu trabalho voluntário; Tempo de pandemia, 2020 descreve o protocolo de atendimento aos pacientes covid-19 e os sentimentos e medos que esta tarefa mobiliza, e Você ama a Cruz Vermelha ou sua família? Perspectivas a partir da covid-19, onde refletem sobre o impacto na saúde em si e na família, sua continuidade ou não na instituição e a perspectiva de vida a partir do sofrimento da doença. O compromisso de apoio e solidariedade como paramédico é profundamente conflituoso devido à emergência sanitária, em que os limites que bordejam a trama de dar ao outro são rompidos diante do sentimento de vulnerabilidade e impotência, no medo de ser infectado e infectar o família e no encontro com a morte, aspectos úteis para os serviços de contenção e apoio que devem ser oferecidos a esses profissionais.

Palavra-chave: angústia, covid-19, medo, paramédicos.

Fecha Recepción: Abril 2020

Fecha Aceptación: Diciembre 2020 
Revista Iberoamericana

de las Ciencias Sociales y Humanísticas

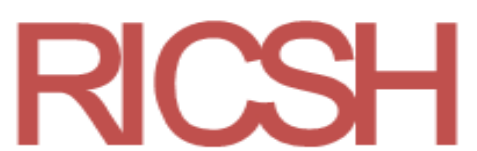

ISSN: $2395-7972$

\section{Introducción}

El 11 de marzo de 2020, la Organización Mundial de la Salud [OMS] declaró a la covid-19 (acrónimo de coronavirus disease, 2019) como pandemia. Días antes, el 27 de febrero se registró el primer caso en México y el $1 .^{\circ}$ de marzo en Chiapas. Ambos afectados regresaron de Italia. La covid-19 es una enfermedad infecciosa causada por coronavirus, que proviene de una extensa familia de virus coronaviridae, cuyo brote inició en Wuhan (China) en diciembre de 2019 (OMS, 2020). Desde entonces, se ha extendido a varios países. Sus manifestaciones clínicas en los pacientes pueden llegar a ser graves y causarles la muerte como consecuencia de la neumonía atípica más inclemente desde la aparición del síndrome respiratorio agudo severo (Sars) en el año de 2002 (Mamzer, 2020).

La profunda desigualdad social y económica genera dispares oportunidades de cuidado, de recursos e insumos para cada pueblo, grupos y sujetos (Santoro, 2020), lo que acentúa las diferencias y posibilidades de los sistemas sanitarios para hacer frente a este

fenómeno global, cuyas consecuencias actualiza aquello que Marcel Mauss (2017) denomina hecho social total, ya que estalla en diferentes ámbitos de la vida. Para Nancy (2020), la covid-19 cuestiona a la civilización en su conjunto, por lo que no es un problema que compete de manera exclusiva a gobiernos o grupos particulares.

En México, las medidas ante sus efectos han considerado la Jornada Nacional de Sana Distancia, la suspensión de clases, el trabajo a distancia, la cancelación de eventos masivos y de actividades en espacios cerrados, la suspensión de actividades no esenciales, de reuniones, así como el confinamiento de la población (Secretaría de Salud, 31 de marzo de 2020). Con estas medidas se intenta limitar la propagación del virus, propuesta que toma como base el número de "camas de reanimación del que dispone cada sistema de salud" (Laurent, 2020, p. 5).

Lo ambiguo de la temporalidad de las medidas implementadas, así como la falta de un tratamiento efectivo, vacunas y la eventualidad de un rebrote en la época de otoño o invierno, al igual que los evidentes problemas económicos, sociales y sanitarios conexos configuran un escenario de suma incertidumbre para la población. Johnson, Saletti-Cuesta y Tumas (2020), en un estudio con una población argentina, concluyen que los sentimientos más recurrentes frente a la pandemia son miedo, incertidumbre y angustia, aunque también responsabilidad y cuidado. Resultados similares se obtienen en España, en un estudio de corte fenomenológico dirigido a enfermeras que atienden a pacientes con covid-19, quienes 


\section{Revista Iberoamericana \\ de las Ciencias Sociales y Humanísticas}

ISSN: $2395-7972$

exponen miedo y desconcierto, pero también responsabilidad, así como falta de recursos, agotamiento y estrés (Andreu, Ochando y Limón, 2020). Para Balluerka et al. (2020):

El malestar psicológico ha aumentado (...), la incertidumbre, la preocupación por padecer o contraer una enfermedad grave (covid19 u otras), y la preocupación por perder seres queridos. Respecto (..) del espectro depresivo, los sentimientos pesimistas o de desesperanza, y soledad (...), es mayor cuando tienen síntomas o han sido diagnosticados de la covid-19, para aquellos que están pasando el confinamiento solos, en mujeres y conforme disminuye la edad, el nivel socioeconómico y la estabilidad laboral (así como) irritabilidad y enfado (p. 124).

Los trabajadores del sistema de salud que atienden o tienen algún tipo de contacto con personas enfermas por covid-19 son algunos de los grupos más vulnerables y de mayor riesgo a contraer la enfermedad, ya que "experimentan una mayor frecuencia de exposición al virus y mayor carga viral en el lugar de trabajo; agravado por un significativo aumento de la carga de trabajo, procedimientos de alto riesgo y baja disponibilidad de equipo protector" (Inchausti, MacBeth, Hasson-Ohayon y Dimaggio, 2020, p. 2), lo que les deja físicamente exhaustos (Blake et al., 2020), con estrés, depresión, ansiedad e insomnio (Anderson, Pooley, Mills, Anderson y Smith, 2020; Lai et al., 2020).

En el artículo En América, el mayor número de contagios de personal de salud: OPS (1 de septiembre de 2020), se cita:

570 mil trabajadores de la salud han enfermado y más de dos mil 500 han sucumbido al virus (...), las mujeres, son las más afectadas, representando casi las tres cuartas partes de los trabajadores de salud diagnosticados con covid-19. En Estados Unidos y México, dos de los países más afectados por la pandemia, los trabajadores de la salud contagiados equivalen a uno de cada siete casos (párr. 2).

Para el 3 de septiembre de 2020 se señalan 1320 decesos confirmados en los profesionales de la salud en México, el más alto en el mundo: “97 mil 632 enfermeros, doctores y otros empleados de hospitales en México han sido diagnosticados con coronavirus desde que comenzó la pandemia, aproximadamente el 17 por ciento de todos los casos en el país hasta ese momento" (México es el país con más muertes entre el 


\section{Revista Iberoamericana de las Ciencias Sociales y Humanísticas}

ISSN: $2395-7972$

personal de salud por Covid-19: Amnistía Internacional, 3 de septiembre de 2020, párr. 8). En Chiapas, "732 de los 22 mil médicos, enfermeras y asistentes que laboran en hospitales se han contagiado de covid-19 y 41 de ellos fallecieron" (Henríquez, 13 de julio 2020, párr. 1). De esta cifra, aproximadamente 4000 trabajadores dejaron de laborar (y no han sido reemplazados) al presentar comorbilidades que ponen en riesgo su vida.

Todo ello irrumpe el sentido de seguridad ontológica, genera miedo y cambios en las relaciones sociales (Mamzer, 2020), pues se ha alterado de manera sustancial la vida cotidiana. La seguridad ontológica proporciona un "sentido fundamental de seguridad de una persona en el mundo e incluye una confianza básica en otras personas (...), necesaria para que mantenga una sensación de bienestar" (Giddens, 1991, p. 37), lo que es indispensable para el disfrute por las acciones que se realizan.

Esta vivencia se actualiza día con día en el personal médico, de enfermería, paramédicos y administrativo que se encuentran en el primer frente de atención a los pacientes con covid-19. En Chiapas, se han destinado trece clínicas de atención respiratoria covid-19 y ocho hospitales reconvertidos, en donde se dispone de un total de 890 camas y 322 ventiladores de asistencia respiratoria (En América, el mayor número de contagios de personal de salud: OPS, 1 de septiembre de 2020). Con la finalidad de apoyar el traslado de personas con síntomas de covid-19 desde diferentes localidades de la entidad, el personal paramédico de la Cruz Roja Mexicana, Delegación Chiapas, lleva a cabo desde el 15 de mayo dichos traslados.

A través de la prensa nacional se ha señalado la condición en que el personal paramédico, como el de la Ciudad de México, sobrelleva los días de agobio y saturación debido a la "sobrecarga laboral, cansancio acumulado (...) de intensas jornadas y soledad" (Solera, 11 de mayo de 2020, p. 8). En función del alto riesgo de contagio a sus seres queridos, algunos de ellos se hospedan en cuartos de hotel que les han sido facilitados, por lo que la lejanía de su familia y la falta de acompañamiento prueban su capacidad para afrontar la soledad.

El trabajo es extenuante, pues el traslado de cada paciente ocupa de dos hasta cinco horas; además, posteriormente es indispensable la limpieza y descontaminación del vehículo y del equipo de apoyo, lo que incluye dos o más horas de trabajo.

Los contagios entre el personal de la Cruz Roja varían de una entidad a otra; de acuerdo con lo referido por Solera (11 de mayo de 2020), para el 22 de mayo en la Cruz 


\section{Revista Iberoamericana}

de las Ciencias Sociales y Humanísticas

ISSN: 2395 - 7972

Roja de la Ciudad de México únicamente se reportó un contagio entre 180 voluntarios y tres en el Escuadrón de Rescates y Urgencias Médicas (ERUM) de 500 elementos. En Tlalnepantla, Estado de México, se reportó el contagio de cuatro paramédicos (Venegas, 8 de mayo de 2020).

El deterioro que sufren los pacientes que trasladan, la enfermedad y el fallecimiento de compañeros de trabajo, aunado al conjunto de problemáticas personales, familiares, profesionales y sociales, les lleva a plantearse el dilema moral de mantenerse en el trabajo o dejar de participar en este (Blake, Bermingham, Johnson y Tabner, 2020). En el estudio llevado a cabo por Anderson et al. (2020) con paramédicos de Australia se expresa que la obligación profesional de este grupo de trabajadores ante situaciones de desastre no debe considerarse de forma ilimitada (Smith, Burkle, Gebbie, Ford y Bensimon, 2019); aun así, indican que existe una obligación personal y organizacional que les lleva a aceptar el riesgo laboral como parte del trabajo (Anderson et al., 2020).

Blake et al. (2020), propone diferentes medidas para sostener las capacidades a largo plazo de los trabajadores del sistema sanitario, entre estas se incluyen los siguientes:

Espacios psicológicamente seguros para el personal, junto con guía y orientación para reducir el estigma social, apoyo de pares y familiares, primeros auxilios psicológicos, estrategias de autocuidado (por ejemplo, descanso, recesos laborales, sueño, trabajo por turnos, fatiga, comportamientos de estilo de vida saludable) y el manejo de las emociones (por ejemplo, daño moral, afrontamiento, culpa, pena, miedo, ansiedad, depresión, prevención del agotamiento y trauma psicológico) (p. 1).

En este proceso deben contar con el apoyo de un equipo multidisciplinario para su propio cuidado, ser informados de manera periódica sobre diferentes aspectos de la pandemia, del proceso de atención a los pacientes y a las familias de estos y establecer servicios de asesoramiento psicológico mediante dispositivos electrónicos (Xiang et al., 2020).

Los paramédicos son parte fundamental del sistema sanitario y las medidas de apoyo para estos son indispensables, pues la crudeza de su experiencia en el trabajo que realizan es un ejemplo de la situación excepcional que vivimos. En este sentido, el presente trabajo tiene como propósito analizar las vivencias del grupo de paramédicos de la Cruz 
Revista Iberoamericana

de las Ciencias Sociales y

Humanísticas

ISSN: 2395 - 7972

Roja Mexicana en torno a la labor que realizan a partir de la emergencia sanitaria por covid-19 en Tuxtla Gutiérrez, Chiapas, México.

\section{El abordaje metodológico}

El estudio se realizó desde una aproximación cualitativa para analizar las experiencias de los sujetos, sus interacciones y comunicaciones. Con esto se trata de “desgranar cómo las personas construyen el mundo a su alrededor, lo que hacen o lo que les sucede en términos que sean significativos y que ofrezcan una comprensión" (Gibbs, 2012, p. 13). Para ello, se consideró un paradigma hermenéutico, que tiene como característica “interpretar y comprender para desvelar los motivos del actuar humano" (Bautista, 2011, p. 48).

\section{Participantes}

Se entrevistó al personal paramédico de la Cruz Roja Mexicana, Delegación Chiapas, en específico a aquellos que participan en los traslados de personas que se presume han sido contagiadas por la covid-19. Esta institución está conformada por personal voluntario de los cuales solo algunos reciben un apoyo económico. En total, está constituida por 12 técnicos en urgencias médicas y 3 en traslados. Estos últimos fueron los participantes: uno de ellos tiene 38 años de edad, estudió la licenciatura en Ciencias de la Comunicación y la maestría en Publicidad. Desde los 16 años participa como voluntario en la institución, primero como tallerista sobre diferentes temas de salud, más adelante como jefe de traslados y en la actualidad como coordinador de los traslados estatales; además, labora como analista de información en el Instituto de Comunicación Social de Gobierno del Estado de Chiapas. Está casado y tiene dos hijos. El segundo de los participantes tiene 46 años, estudió como profesional técnico en Enfermería General y técnico en Urgencias Médicas, se incorporó desde hace 30 años a la Cruz Roja en la ciudad de Comitán de Domínguez, Chiapas, y actualmente colabora como paramédico en la atención de pacientes en el área de traslados. Trabaja también como empleado en una unidad de la Secretaría de Salud. Es casado con dos hijos. La tercera participante tiene 26 años de edad, estudió la licenciatura en Gerontología y técnico en Urgencias Médicas, colabora en la institución desde hace ocho años y hace poco más de un año fue asignada al área de traslados. Es soltera y vive con la madre y la abuela materna. 


\section{Técnicas e instrumentos}

Se aplicaron entrevistas semiestructuradas para "obtener descripciones del mundo de la vida del entrevistado con respecto a la interpretación del significado de los fenómenos descritos; tiene una secuencia de temas que se han de cubrir, así como algunas preguntas propuestas” (Kvale, 2011, pp. 79-80). En el proceso se admitieron cambios en la secuencia y forma en que se plantearon las preguntas para profundizar en los temas de interés.

De inicio, se incluyó la recuperación de datos generales de los entrevistados, como edad, escolaridad, antigüedad como paramédico, antigüedad en la institución, días y horarios de servicio, estado civil, si tiene o no hijos y otra ocupación. Las preguntas y los temas que se exploraron fueron los siguientes:

¿Cómo te iniciaste en la labor de paramédico? (intereses, formación o capacitación, expectativas, función, actividades que realizaba previo a la emergencia sanitaria y riesgos en el trabajo).

¿Cómo ha sido tu labor a partir de la emergencia sanitaria por covid-19? (funciones y actividades-cambios o continuidad en estos/as, expectativas al inicio de la pandemia y en la actualidad en torno de su trabajo, vivencias más recordadas en que ha participado: traslados, enfermos graves, personas que han fallecido en el trayecto, sentimientos ante el contagio, situación ante la enfermedad — si ya ha sido contagiado, preocupaciones en torno a la salud o situación de su familia de origen, nuclear o extensa-, riesgos).

\section{Procedimiento}

El proyecto fue avalado científica y éticamente por el Comité Académico de la Facultad de Ciencias Humanas y Sociales de la Universidad de Ciencias y Artes de Chiapas. El contacto con los participantes se realizó a través de personas conocidas; se les abordó vía telefónica para comunicarles los aspectos más relevantes del estudio y su participación; se les indicó que la información se trataría de forma confidencial y anónima. Aceptaron colaborar de forma voluntaria, autorizaron el uso de la información con fines de investigación y se obtuvo su consentimiento informado. Las entrevistas se aplicaron en varios momentos durante el periodo de julio a septiembre de 2020, incluso, mientras se encontraban enfermos. Este trabajo en la modalidad en línea se plantea como opción de investigación "en contextos de confinamiento, de bajo o inviable contacto físico" (Hernán, Lineros y Ruiz, 2020, p. 2). 
Revista Iberoamericana

de las Ciencias Sociales y

Humanísticas

ISSN: 2395 - 7972

\section{Análisis de la información}

En este proceso, se siguió la propuesta de Gibss (2012), quien plantea su inicio con la preparación de los datos, para lo cual se transcriben las entrevistas, se elabora un primer esbozo de su contenido, que incluye las notas de trabajo sobre lo acontecido en el proceso de entrevista. Una siguiente fase, que ocurre paralelo al proceso de recogida de datos y su transcripción, es la de la redacción de las notas de trabajo de campo, los memorandos y, en suma, el inicio de la redacción del trabajo. Le sigue la codificación temática y codificación, fase donde se segmenta la información y se generan las unidades de análisis, las cuales a su vez se categorizan; en este proceso, la organización de los conceptos y temas emergen de la propia información compartida por los entrevistados. Finalmente, se realiza la narrativa de la historia sobre los temas que posibilitan una comprensión más amplia de esta. Lo anterior se reflexionó a la luz de las condicionantes sociales y contextuales en que realizan su labor y desarrollan su vida cotidiana.

\section{Resultados}

El proceso de análisis de la información posibilitó la estructuración de tres bloques temáticos: El amor a la camiseta en la Cruz Roja, en el cual se comparte el tipo de actividades que realizan en la institución, el sentido de su tarea como voluntario, así como la tensión inherente a la labor que llevan a cabo. El segundo de ellos -Tiempo de pandemia, 2020 - describe el protocolo de atención a pacientes covid-19, los sentimientos y afectos que moviliza esta tarea, el desgaste físico en las situaciones de traslado, la demanda constante de familiares para el ingreso de los pacientes a las clínicas y el infortunio de la espera. En el último bloque - denominado ¿Quieres a la Cruz Roja o a tu familia? Perspectivas a partir de la covid-19- se reflexiona sobre la afectación a la salud en ellos mismos y su familia, su continuidad o no en la institución y la perspectiva de vida a partir de la enfermedad del coronavirus que han sufrido.

\section{El amor a la camiseta en la Cruz Roja}

Los paramédicos tienen 8, 22 y 30 años colaborando en la Cruz Roja, institución en la cual todos son voluntarios, aunque algunos reciben una remuneración exigua, que no se corresponde con la trascendencia ni con el horario y riesgo que supone el desarrollo de sus 


\section{Revista Iberoamericana \\ de las Ciencias Sociales y Humanísticas}

ISSN: 2395 - 7972

tareas. Su preparación es constante, lo cual es un requisito para recertificarse anualmente, cualidad esencial del voluntariado de emergencias (Soler, 2007).

La invitación a colaborar en la institución les llegó por diversas vías antes de los 18 años, pero en estas coincide un sentido humanitario del servicio y apoyo al otro.

... esto se hace ipor pasión de querer servir y ayudar a la gente!

(Antonio).

... ayudar a la gente cuando sufre una urgencia, lo primero que vemos en un familiar o en el mismo paciente es desesperación, jel querer que lo ayuden!, entonces nosotros lo confortamos, con ayudarlo, con verlo, en darle el tratamiento adecuado (...), el otro poquito es el amor a la camiseta, el estar muchos años en la Cruz Roja ya le traemos algo como un amor más a nuestra vida (Ignacio). Me llamó la atención la labor humanitaria, además lo de atención y ayudar a los demás (Lucía).

El aprendizaje de la tarea de paramédico es amplio y diverso, pues incluye la capacitación, la experiencia práctica y el acompañamiento y tutelaje por otros. Día a día, se preparan para lo imprevisto, cada uno alista el equipo que le corresponde, a sabiendas de que con ello podrán realizar su tarea de cuidado hacia los otros y a ellos mismos.

... por costumbre tengo siempre revisar mi unidad, de limpiarla, de barrerla, de trapearla y lo sigo haciendo hasta la fecha, pero ya más detallado (Lucía).

... al llegar a la guardia, lo que se tiene que hacer es revisar la ambulancia, que tenga el equipo y el material básico necesario (Antonio).

... como operador tengo que revisar la unidad cada vez que llego a la Cruz Roja, checar lo que son aceites, la gasolina, la revisión del vehículo por afuera, que es la carrocería, las llantas, para que no vayamos a tener una falla al realizar el traslado. Al finalizar toda la jornada laboral, tengo que checar otra vez el mismo procedimiento que es que quede con gasolina, se lava el vehículo (...), hacemos un reporte diario de cuántos traslados realizamos al día, qué tipo de 
pacientes, personas que sufrieron fracturas, que iban a un estudio o a un hospital (Ignacio).

A lo largo de las jornadas extenuantes en los años que tienen como voluntarios, algunos de los servicios que han realizado les han dejado un recuerdo imborrable; en ellas dejan entrever sus propios miedos, carencias y ausencias, pero también del horror de la muerte.

... un hecho así muy marcado, como el caso de un bebé de dos años de edad que se cayó en una cisterna, desafortunadamente se nos avisó ya tarde y no pudimos realizar nada (con pesar) (Antonio). ... en un servicio, un niño de aproximadamente cinco años estaba todo ensangrentado, lo que hice fue cargarlo, pero me recordó mucho un suceso que me pasó a mí, que también me había rajado la cabeza, ime iba a desmayar! y ahí reaccioné y dije: “'O me quedo en Cruz Roja o me salgo de Cruz Roja!, porque no voy a soportar la sangre”. Ahí fue donde decidí que sí me iba a quedar (Ignacio).

... un servicio de la semana pasada, en un accidente, ifue la primera vez que un paciente se me fue!, fue la primera vez, la paciente estaba grave, tenía un TCE (traumatismo cráneo encefálico) severo, pero ¡ella venía muy combativa y no pude hacer más!, ¡no pude ver el oxígeno!, ¡no pude checar signos vitales!, la tuve que sostener porque se estaba moviendo mucho (...), por lo mismo del TCE estaba con su tono completamente alterado y ino sabía qué hacer!, tomé la opción de sostenerla porque no pude hacer más y como 30 segundos antes de llegar al hospital falleció (...), iba sola en la parte de atrás (Lucía).

Además, es una tarea demandante, de alta tensión. Como refieren, "de mucha adrenalina".

... todo lo que engloba Cruz Roja en sí es bonito, se maneja mucha adrenalina, mucho estrés (...), del debate entre la vida y la muerte, en que la atención que pongas y la capacitación que tengas puede depender que esa persona viva (Antonio). 
... la satisfacción de llevar los pacientes, si salió o ya no pudo sobrevivir, jes la adrenalina que te ayuda a sacar ese momento!, que nos digan no es lo mismo que vivirlo, isentir el momento!, porque muchos compañeros decían: "Ha de ser difícil llevar un paciente covid”, y, pues, el primer traslado lo realicé yo de aquí en Tuxtla Gutiérrez (Ignacio).

\section{Tiempo de pandemia, 2020}

En la atención de la pandemia, se cumple el protocolo sanitario de protección y atención a pacientes, lo que genera expectativas, miedo e incertidumbre. Al inicio no participaron en el traslado de pacientes con sospecha de covid-19; sin embargo, en los servicios llevados a cabo, tenían que considerar las afecciones respiratorias del paciente y con ello el temor al contagio. Más adelante, con la realización de traslados, la espera, la desesperanza, el cansancio y la angustia llegaron al límite de su fortaleza.

... el Covid-19, iclaro que es totalmente distinto el manejo!, desafortunadamente, como en la mayoría de las instituciones de salud el abasto de insumos siempre llega un poco tarde, al principio no empezamos con lo de atención a pacientes con estas características, en sí, ¡no se sabía quién sí y quién no!, de todos modos tenías que estar preparado, capacitado y con el equipo necesario de protección, pudo haber ocurrido un accidente y en ese accidente vino una persona infectada, entonces tienes que ir preparado, con medidas sanitarias de protección, porque siempre va a existir la incertidumbre, el temor a que te puedas infectar (Antonio).

El dilema por ser o no parte de una tarea de sumo riesgo les ha confrontado con sus principios de servicio y ayuda al otro:

... en un principio dices: "Bueno, ¿y ahora qué hago?, ¿y si no tengo equipo, el traje necesario o indispensable para poder protegerme?, ¿le entro o no le entro?’. En un principio esa era la indicación que teníamos, de que si no teníamos el equipo necesario de protección no íbamos a atender a pacientes (Antonio). 


\section{Revista Iberoamericana \\ de las Ciencias Sociales y Humanísticas}

ISSN: $2395-7972$

El imaginario del contagio generó temor y angustia, condición que fue parte de la cotidianidad con el inicio de pacientes infectados en la entidad desde el $1 .^{\circ}$ de marzo hasta el 15 de mayo de 2020, fecha esta última en que iniciaron con el equipo necesario los traslados de pacientes sospechosos de covid-19. Durante dos meses y medio, la cotidianidad se tiñó de la angustia por el contagio, pero esta se exacerbó con el traslado de pacientes infectados.

¡Me daba mucho miedo!, piensas en ti y en lo que te puede pasar, y ¿qué pasa con tu familia?, yo a mis 30 años (de servicio) es la primera pandemia que me toca y te sientes ;muy vulnerable!, te sientes jcon mucho temor! (Antonio).

Al principio fue con temor, sí, temor, ifue miedo la verdad! (...), nos agarró como una crisis de ansiedad jla verdad!, porque cuando nos dijeron: “¿Saben qué?, vamos a empezar a hacer los traslados de pacientes covid". Y, pues, tenemos familia, nos podemos contagiar (Ignacio).

... no piensas tanto por ti misma, pienso más ipor mi familia, mi abuelita, mi mamá!, que son personas vulnerables ante esa enfermedad (...), mi abuelita sale mucho, ella trabaja también en un hospital, mi mamá tiene venta de servicios de alimento y está en mucho contacto con la gente (Lucía).

La pandemia dejó fuera del servicio a muchos voluntarios, quienes por el temor a contagiarse o por su propia seguridad — ya que presentaban comorbilidades que les ponían en mayor riesgo- abandonaron el servicio.

Para paliar el temor optaron por hablar entre ellos y comentar esta situación, lo que permitía desahogar la tensión, hacer palabra la angustia y atraparla en el discurso:

... platicábamos de los pacientes que podríamos tener y que nos podríamos contagiar, sentía un poco de temor porque, pues, estaba con mi familia (Ignacio).

$\mathrm{Al}$ iniciar los traslados tuvieron que habituarse al uso del equipo, el cual incluye diversos aditamentos, es sumamente pesado y por el material del que está elaborado resulta muy caluroso. Además, considera una rutina y apoyo para su colocación, uso y desinfección. 
Revista Iberoamericana

de las Ciencias Sociales y

Humanísticas

ISSN: $2395-7972$

... el equipo de bioseguridad consta de un overol marca Tyvek, te colocas lo que son googles, gorritos quirúrgicos, las mascarillas kn95, bata con el calzado y yo en mi caso me pongo tres pares de guantes, seguridad también para arriba de la mascarilla kn-95, tenemos unos de esos cubrebocas que de hecho lo hace un poco más seguro para la parte de aquí de la cara (Lucía).

... con el traje sudamos demasiado y nos deshidratamos, jes bastante pesado! (...), con el cubrebocas nos hace falta el aire y no podemos ni respirar (Ignacio).

... utilizamos unos googles, a veces se empañan y se nos borra la visión, tenemos que caminar como astronautas porque no podemos ver completamente. Lo máximo que hemos tenido un equipo completo es de cinco a seis horas (Ignacio).

En un servicio de traslado, desde la llamada de ayuda hasta su término, ocupan de dos a cinco horas de trabajo. En este periodo, deben tomar en cuenta los signos vitales del paciente y evitar la propagación del virus en el equipo y en la ambulancia, a lo que se suma la carga del traje y el sofocante calor que en Tuxtla Gutiérrez ha sido de 32 a $34{ }^{\circ} \mathrm{C}$.

Es muy complicado usar el traje, tienes que saber manejar tu estrés, sientes hasta asfixia, jes desesperante! (...), casi no sientes nada, no sientes el olor del exterior, jes muy complicado!, el temor de si se te rompe algo, si se te mueve la careta o el cubrebocas puedes infectarte, entonces lo evitas y tienes que cuidarte (Antonio).

... es pesado tener el equipo, nos estresamos, hemos llegado a presentar hasta pequeñas insuficiencias respiratorias por tener tanto tiempo las mascarillas y no poder respirar (...). Habían traslados que nos tocaban tres o cuatro de la tarde, entonces estaba el calor ¡insoportable!, llegábamos a donde estaba el paciente y a veces lo teníamos que bajar del primer piso con todo el equipo, a veces ya estaban en la primera planta, pero habian pacientes que estaban demasiado gorditos, entonces sí era complicado poderlo mover (...), tenemos una cápsula en que tenemos que meter al paciente para evitar la contaminación dentro de la ambulancia y hacia el personal 
(...), todo eso se nos complicaba bastante, más el estrés que nos generaba que era un paciente crítico, llegábamos (a la clínica) y en varias ocasiones hasta cuatro o cinco horas teníamos que esperar para que nos pudieran recibir al paciente y con todo el equipo (Ignacio).

Al término de un traslado, deben completar el protocolo; para ello, es indispensable la desinfección del vehículo, el equipo y su persona, Todo ello mientras tienen aún puesto el traje y han trascurrido de dos y hasta cinco horas de trabajo acompañando la atención de un paciente en estado crítico con una prolongada espera para su ingreso a una clínica covid19.

... hay un proceso para podernos desinfectar tanto nosotros como la unidad que lleva aproximadamente una hora y media (...), hay un área específica, aislada completamente de todo el personal y las ambulancias. Llegamos y tenemos con el mismo traje que desinfectar toda la unidad, por dentro y por fuera con cloro, al 100 $\%$, limpiar la camilla, el taburete, todo lo que utilizamos, la cápsula donde metemos a los pacientes con covid, después nos vamos quitando por pasos el equipo para tratar de no infectarnos, primero los guantes y nos ponemos gel, nos quitamos la careta y luego los googles y los cubrebocas, todo el equipo. De ahí tenemos que pasar a otra área para desinfectarnos nosotros, con otros líquidos que no nos hacen daño (...), estamos sumamente sudados, deshidratados después de hacer toda la limpieza, cuando estamos desinfectados, entonces ya podemos tomar agua, alrededor de cinco horas desde que se hace todo el proceso y si no habíamos comido, pues teníamos que comer, yo presenté dolores de cabeza (...), todo ese tiempo que salimos no tomamos agua, no podemos ni comer nada absolutamente nada (Ignacio).

Los traslados en dos meses de trabajo, descontando las semanas en que resultaron infectados, fueron de casi uno por día. 
Revista Iberoamericana

de las Ciencias Sociales y

Humanísticas

ISSN: 2395 - 7972

... del 15 de mayo a la fecha he realizado 22 traslados de pacientes con covid, de jóvenes de 35 a 40 años y de la tercera edad de 50 a 65-70 años (Ignacio).

En dos meses, llevo unos 29 traslados (Lucía).

Yo llegué a hacer dos, pero los demás compañeros habían hecho hasta tres o cuatro en un turno, cuando se dio la curva importante de contagio, entonces tenían que intervenir dos ambulancias, eran hasta seis por turno (Antonio).

¡Salíamos muy estresados!, cuando terminábamos jno queríamos nada! (Ignacio).

El protocolo de traslado es sumamente estricto, ello significa el cuidado para evitar la contaminación de cualquier parte del equipo y del vehículo:

... cuando se realiza un traslado se llega a tener contacto directo con el paciente, pero se trata de que el familiar apoye, por ejemplo, si se tiene que poner una punta nasal al paciente le explico cómo lo tiene que colocar y lo realizan (Lucía).

... para el protocolo de pacientes tenía que manejarse una cápsula, no podías intubar a pacientes, aspirar secreciones, jes muy desesperante ver a una persona que se está muriendo!, ise está asfixiando!, es frustrante no poder ayudar, más que sabes hacerlo, pero el protocolo te dice: “No debes de hacerlo!”, ¡no!, por el riesgo sanitario que existe, eso ya tiene que ser directamente en una unidad hospitalaria, en una unidad de terapia intensiva (Antonio).

La demanda de los pacientes acentúa la tensión, ya de por sí elevada por el equipo que portan, la inclemencia del clima, la espera a que sean atendidos y la imposibilidad de apoyarlos más debido al protocolo seguido, así como a la falta de espacios en las clínicas para su atención.

Hemos visto pacientes ¡muy críticos!, ¡тиy, mиy críticos!, son pacientes que directamente se van a un hospital para poderse intubar, es bastante fuerte la manera en que nos piden apoyo, quisieran sentir más oxígeno porque no pueden respirar (...), hay familiares que nos piden de favor, ique nos ruegan que veamos la 
manera de que puedan ingresar los pacientes a los hospitales!, ique le pongamos más oxígeno, que veamos que pueda respirar! (...), en clínicas covid no es ingresar como si fuera un hospital normal, teníamos que llegar, esperar que saliera el personal del hospital para valorar al paciente ;afuera!, para ver si lo podían recibir o no, si había espacio, si ameritaba que entrara, tardábamos hasta cinco horas y el paciente tenía que estar arriba de la ambulancia porque no lo podíamos bajar, habían pacientes que tenían que tener oxígeno, el oxígeno a veces nos tardaba hasta dos horas y media y teníamos que pedir oxígeno a los hospitales, entonces todo eso hacía que se pusiera más crítico (...), las salas de varios hospitales estaban llenas, bastante saturadas (...). Cuando nosotros entrábamos, pues ¡no había espacio, no había cama, no había lugar!, no era tanto de que ellos no quisieran ingresar (al paciente), pero ¡no había lugar! y la mayoría de todos los pacientes que estaban adentro, como el 60 o $70 \%$ estaban intubados iyo mismo los vi! (...), en un hospital llegábamos a tener hasta tres ambulancias paradas ahí (...), hubieron compañeros que dos veces fallecieron los pacientes, jahí en la ambulancia! (Ignacio).

Las dificultades de atención les generaron conflictos frecuentes con los familiares de los pacientes trasladados, quienes les instaban a ingresar a estos a la clínica. Ellos mismos se muestran impotentes, enojados por esta situación.

... los familiares de una paciente estaba viendo en qué momento me soltaban un golpe, estaba muy encabronado el señor, la paciente estaba algo inestable, nada más estaba esperando que no se me fuera a morir ahí arriba de la ambulancia y se me fuera a mi toda la... su familia, porque ahí estaban empezando a querer agredirnos (...), se siente uno vulnerable, porque vas con el traje, vas cuidando de que no te infectes, que no se te vaya a romper el traje, que la careta no se te caiga o los lentes no se te empañen, no sé cómo es que hay guardia nacional fuera de los hospitales y solo uno hay, entonces ¿qué va a hacer uno con toda la familia del paciente?, es 
Revista Iberoamericana

de las Ciencias Sociales y

Humanísticas

ISSN: 2395 - 7972

mucha la vulnerabilidad que tenemos afuera de un hospital y ino hay quien te ayude!, mi compañero y yo no podemos hacer más porque no tenemos ni celular ni nada como para contactar a alguien (Lucía).

Nos sentimos enojados porque es una vida que está en peligro (Ignacio).

Este proceso ha acompañado los aprendizajes sobre la enfermedad y ha advertido la importancia del equipo de apoyo.

... he tenido mucho aprendizaje viendo tantos pacientes con covid, es más fácil identificar los síntomas y lo que sí es muy preocupante, cómo de un ratito a otro se desaturan, están en 80 y cuando le quitas el oxígeno le baja a 60, te das cuenta qué tan frágil es uno, qué tan necesario es un tanque de oxígeno para que puedas seguir subsistiendo. Me pongo a pensar, jojalá no me toque! y si me llega a tocar, jojalá no sea tan grave! (Lucía).

\section{¿Quieres a la Cruz Roja o a tu familia? Perspectivas a partir de la covid-19}

A medida que pasaron los días, algunos de los paramédicos enfermaron; incluso uno de sus compañeros falleció por el contagio, situación que les colocó ante la disyuntiva de continuar o no con su tarea.

... la verdad nos pegó cuando supimos que un compañero de nosotros, pues, desgraciadamente falleció (...), era paramédico, cuando a él lo ingresan al hospital nos enteramos de que falleció, ¡eso sí fue bastante fuerte!, porque teníamos contacto con él y nos decía que estaba bien, que ya iba de salida, cuando un día nos despertamos ya había fallecido. El otro compañero es mi pareja en la tarde de traslados, a Antonio (otro de los entrevistados), le pegó bastante fuerte, hasta decirnos de que ya no la iba a librar, eso isi nos desanimó bastante! o al menos a mí sí, jsi me bajó mucho, mucho, mucho el ánimo!, pero jya está de salida!, iya va para arriba!, pero esas dos ocasiones sí nos pegó, no solamente a mí, ja todos los compañeros!, varios compañeros ya no querían salir a los 


\section{Revista Iberoamericana \\ de las Ciencias Sociales y Humanísticas}

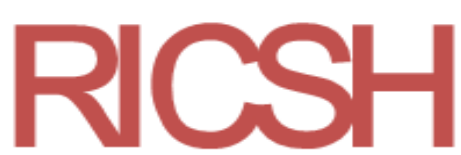

ISSN: 2395 - 7972

traslados covid porque se iban a contagiar y tenían familia (Ignacio).

... dos compañeros sí se pusieron graves, uno de ellos fue mi amigo Toño (otro de los entrevistados), yo le hice el traslado, fue como ;lo más jodido que me pudo haber pasado de todos los tiempos que he estado aquí en Cruz Roja!, ver que yo convivo con él y después verlo como paciente isí me dolió muchísimo!, de hecho lloré ese día ahí en la ambulancia con él, porque me dio mucha tristeza verlo ahí en la unidad, luego, me mandó un mensaje de que si pasaba algo, nos dio a entender que ya sentía que se iba, y sí, ¡me “cagué” muchísimo en ese momento!, ;sí fue feo ese día la verdad! (Lucía).

Ante la enfermedad de los compañeros, el temor y el miedo fue la constante en cada uno:

¡Miedo!, porque ese último día que los vi a los dos estábamos juntos, y a la hora que nos dicen que tienen covid estuve con esa espinita como una semana, checándome temperatura, viendo mi saturación, si no me dolía el cuerpo o algún dolorcito de la garganta, estuve paniqueada así por muchos días (Lucía).

Ser el transmisor de contagio a la familia se mantiene permanentemente en el imaginario de los paramédicos; por una parte, desean continuar su labor de ayuda y, por otro, se encuentran en el límite de dicho principio, cuando el riesgo es tan alto que genera miedo:

... me entra miedo el pensar que vayan a salir siendo las próximas

(la madre y la abuela), que yo las tenga que salir a atender, luego ya está complicado buscar oxígeno y luego buscar los medicamentos, eso realmente me preocupa (Lucía).

Ante el contagio que ocurre a las dos semanas de iniciar los traslados, se reactivan y actualizan los miedos a que la familia enferme y se revalora su continuidad o no en la institución.

En dos de ellos su familia enfermó. En el caso de Ignacio, su esposa estuvo enferma. Ella mostró síntomas de dificultades respiratorias, cefalea y mareo, y aunque 


\section{Revista Iberoamericana \\ de las Ciencias Sociales y Humanísticas}

ISSN: 2395 - 7972

tuvieron contacto con sus hijos, no presentaron síntomas. En el caso de Antonio, también enfermaron su esposa e hijos, aunque igualmente no tuvieron síntomas graves.

De los paramédicos, Ignacio presentó dificultades respiratorias, cefalea, insomnio y ansiedad. Estuvo convaleciente dos semanas y a la tercera regresó a su trabajo. En el caso de Antonio, requirió incluso hospitalización. Sobre su enfermedad refiere:

... a mí me tocó muy difícil, estuve en un proceso de dificultad respiratoria con manejo de oxígeno, fue algo complicado. Llevé todo el protocolo como lo marca la Secretaría de Salud, tuve aislamiento, tuve tratamiento y mi esposa fue la que estuvo conmigo, ella fue la que me estuvo asistiendo, estuve aislado.

Las dudas sobre continuar o no en el trabajo se relacionan con las demandas familiares, la incursión en otro tipo de tareas en la misma institución y la valoración del altísimo riesgo que mantienen en las tareas que llevan a cabo, sobre todo de contagiarse nuevamente.

... ahorita no, no siento estar recuperado como tal para volver a reincorporarme al sistema (...). Son cambios que tiene uno que dar, la familia, la misma salud. Si voy a regresar nuevamente al manejo de pacientes covid, tengo el riesgo de infectarme otra vez, aparte, pues, también estoy con patologías crónicas degenerativas que también tengo que manejar (...), mi condición física ya no es la misma a la de un chavito de 18, 19 o 20 años que va a soportar mejor una situación de rescate (...), (mi familia) comparten mi situación, mi forma de pensar y hasta cierto punto pues también están apoyándome en el proceso de dejar esto, siempre hay esa problemática de “¿quieres a la Cruz Roja o quieres a tu familia?”, desafortunadamente hay momentos en que te absorbe mucho la Cruz Roja, de no estar con tu familia (...), llega un momento en que también ellos (sus hijos) reclaman lo que es la estancia con ellos, la convivencia (Antonio).

La enfermedad le llevó a reflexionar en torno de su salud. A ello se sumaron cambios en su alimentación, activación física y consumo de tabaco. 


\section{Revista Iberoamericana}

de las Ciencias Sociales y Humanísticas

ISSN: 2395 - 7972

... yo era, isoy una persona obesa, diabético, hipertenso!, condiciones muy favorables para el covid, muy complicadas también para el manejo de la sintomatología (...), ahorita estoy en un proceso de alimentación digamos adecuada, no chatarra, no refrescos, más sano y más saludable, hacer ejercicio, porque no me daba tiempo para hacerlo, porque ¡no quería yo hacerlo! Afortunadamente aquí estoy, gracias a Dios, y sí, sufrí un cambio muy positivo. Es otra oportunidad de cambiar, de hacer cosas para ti y tu familia. Le cambia a uno la perspectiva, ahorita la forma de ver las cosas es totalmente distinta en todos los aspectos (...), más comunicación, más relación en pareja con mis hijos, esta pandemia ha dejado cosas muy malas, pero también muy positivas, cosas de reflexión, si uno lo quiere ver así, de realmente con quien estás, quienes están contigo, en la cuarentena como dicen, realmente te das cuenta quiénes son tus amigos, quién es tu familia y quién está contigo y quién no, quién está nada más por estar ahí, 2020 va a estar muy marcado para mí y para muchos (Antonio).

\section{Discusión}

Las vivencias expresadas por los paramédicos testimonian el sentido de su tarea, de responsabilidad y solidaridad con el otro desconocido, principios de labor profesional que a su vez les prodiga sostén ante sus propias carencias, ya que el dar tiene como sentido la propia recuperación de sí. Por otra parte, la crudeza del encuentro con el enfermo y la muerte, ante un sistema sanitario desbordado, concentra la angustia e impotencia ante el vacío de certezas para el otro y su devenir, así como una continua autorreferenciación por el riesgo de enfermar o que enfermen su familiares, lo que genera un profundo sentido de vulnerabilidad.

En una sociedad individualista, ¿qué moviliza a ayudar al otro? Lipovetsky (1990) señala que un compromiso transformador, en que se configuran significados que reivindican la solidaridad y participación activa en la comunidad. De responsabilidad por la sociedad en que vive, el colocarse en el lugar del otro, ser empático y mostrar afectación por lo que le ocurre es — como señala Soler (2007) — una de las características esenciales 


\section{Revista Iberoamericana de las Ciencias Sociales y Humanísticas}

ISSN: $2395-7972$

del voluntariado. La identificación de lo propio en el otro gesta el compartimiento de su vivencia, con lo que es posible comprender su experiencia de dolor, de angustia y hartazgo, de entender lo que le sucede (Aucion, 2018); pero es en este mismo proceso en que se realiza la ayuda al otro, sobre todo de niños o enfermos, en donde es posible redimir y recuperar para sí lo perdido o la falta en la propia historia.

Tal como refieren Inchausti et al. (2020) y Blake et al. (2020), la exigencia y alto riesgo del servicio que realizan les constituye en un grupo vulnerable, con excesiva carga de trabajo, miedo y angustia. De hecho, al miedo lo acompaña un sentimiento de desamparo no reconocido, expresión de la dificultad para simbolizar y comprender la experiencia que deviene en tensión corporal (Silva, 2015), el cual opera como recurso para evitar sumirse en una condición de fragilidad. El miedo aloja la falta de una condición ordenadora.

En su forma extrema, puede llevar a ataques de pánico, que — de acuerdo con Silva (2015) — “es la expresión de una falla abrupta, generalmente momentánea, de la facultad de simbolizar, pensar y comprender la experiencia" (p. 106). Ello ocurre sobre todo en aquellos que presentan algún tipo de vivencias de desamparo y han tenido que asumir desde muy temprana edad la responsabilidad de sí mismos, como sucede con los tres participantes de esta investigación.

Cuando tal condición de vulnerabilidad, de miedo y angustia se mantiene de forma prolongada, se afecta la seguridad ontológica del sujeto (Giddens, 1991), y con ello el sentido de disfrute por el cumplimiento de la propia actividad.

El reconocimiento de los propios límites de las condiciones físicas o padecimientos, cualidades que deben ser óptimas para desempeñarse en emergencias, dan cuenta del proceso reflexivo que supone el no tener que dar al otro sin medida, pues "no debe caer en la trampa del salvador que se desentiende de sí mismo en pro de otras personas" (Soler, 2007, p. 22), sobre todo cuando los fallecimientos son una constante.

La pena por quien muere muestra la respuesta humana para asir lo que se ha interiorizado a razón del otro: "Todo recuerdo, memoria, afecto y expresión trabaja como reconocimiento a lo que fue la vida" (Hernández y García, s. f.).

Vida o muerte no son comprensibles si no existe la posibilidad de pensarlas, de cuestionarlas, de considerarlas en relación con la propia existencia, para razonarlas y colocar en perspectiva las inquietudes, zozobras y expectativas, para dar cuenta de lo que se 


\section{Revista Iberoamericana \\ de las Ciencias Sociales y Humanísticas}

ISSN: 2395 - 7972

tiene y no se comparte. Más allá del compromiso y solidaridad al otro comunitario, parece difícil acceder a la mirada del otro (familia, esposa, hijo, hija), mostrar afecto como a quien se cuida en el servicio, solo que este demanda palabra y contacto, realizar con la misma exigencia con que se cuida el protocolo de traslado, limpieza y desinfección, el acompañamiento en la tarea doméstica, en la tarea del hijo, de su ropa y elaboración de alimentos, de revitalizar el cansancio de afuera para compartir la rutina hogareña. Lo que se encuentra en entredicho es la ausencia por el disfrute en la vida cotidiana, de lo olvidado en la búsqueda del servicio al otro, del falaz ocultamiento de la ausencia.

Los hallazgos, tal como lo proponen Blake et al. (2020) y Xiang et al. (2020), señalan la imperiosa necesidad de crear servicios de apoyo para estos y otros profesionales de la salud con la finalidad de mantener sus capacidades a largo plazo.

\section{Conclusiones}

La pandemia devela de manera tortuosa las desiguales condiciones en que los sistemas sanitarios y su personal vivencian la atención de pacientes con covid-19. La espera para el ingreso de los pacientes, el ocupar de dos a cinco o más horas para su traslado y el fallecimiento de estos en la propia ambulancia ante la imposibilidad de ser internados en las clínicas exhiben las condicionantes económicas, culturales y sociales con que se realizan los servicios a la comunidad y a sus ciudadanos. Como institución, el Estado no acompaña la tarea que emprenden a través de servicios interdisciplinarios y psicológicos de contención, que atiendan las problemáticas personales y laborales que presentan.

La reflexión de lo que acontece con los paramédicos incluye distintos ámbitos. De inicio, debe recuperarse su tarea, el compromiso social y responsabilidad comunitaria que tenemos como ciudadanos y sociedad en su conjunto, indispensable, ahora más que nunca, en tiempos de pandemia; por otra parte, en términos de su propia subjetividad, la angustia y miedo, son recursos psíquicos que muestran las dificultades para elaborar la experiencia, totalmente comprensibles ante lo tóxico de su vivencia; finalmente, su reflexión - a partir de la enfermedad y el imaginario de la muerte - revitaliza lo que no ha sido posible advertir y disfrutar en la cotidianidad de sus relaciones, además de las faltas, de las ausencias que dejaron huella en su historia. El presente es una oportunidad de elaborarlas para asumir, como dice uno de ellos, otra perspectiva, llenar las faltas no solamente con el otro desconocido, sino con todos aquellos/as que guardan un especial significado en sus 
Revista Iberoamericana

de las Ciencias Sociales y

Humanísticas

ISSN: 2395 - 7972

vidas. Si se quiere y se atreven a verlo así, la covid-19 dejará huella no solo de sufrimiento - necesario para elaborar la experiencia a través de la palabra—, sino también de una nueva oportunidad de repensar y reconstruir su propia historia.

\section{Futuras líneas de investigación}

La información expuesta, vislumbra algunos temas de sumo interés para estudios ulteriores. Entre estos, destaca el análisis de las condiciones en que operan los sistemas sanitarios, así como los apoyos que se brindan al personal del sector salud por parte del Estado y las diversas instancias de gobierno; por otra parte, la reflexión en torno del compromiso social y comunitario de la ciudadanía, es sin duda un imperativo en este tiempo y otros venideros. Estudios a más largo plazo, podrán también dar cuenta de los efectos de las condiciones de vulnerabilidad a que es expuesto este tipo de personal en eventos tan excepcionales como el de la pandemia.

\section{Referencias}

Anderson, C., Pooley, J. A., Mills, B., Anderson, E. and Smith, E. C. (2020). Do paramedics have a professional obligation to work during a pandemic? A qualitative exploration of community member expectations. Disaster Medicine and Public Health Preparedness, 1-7. Doi: https://doi.org/10.1017/dmp.2020.212

Andreu, D., Ochando, A. y Limón, E. (2020). Experiencias de vida y soporte percibido por las enfermeras de las unidades de hemodiálisis hospitalaria durante la pandemia de Covid-19 en España. Enferm Nefrol., 23(2), 148-59. Recuperado de http://scielo.isciii.es/pdf/enefro/v23n2/2255-3517-enefro-23-02-148.pdf

Aucion, E. (2018). Empathy Leads to death: why empathy is an adversary of capital defendants. Santa Clara Law Review, 58(1), 98-136. Retrieved from https://digitalcommons.law.scu.edu/lawreview/vol58/iss1/3/

Balluerka Lasa, N., Gómez Benito, J. y Hidalgo Montesinos, M. D. et al., Santed Germán, M. A. (2020). Las consecuencias psicológicas de la Covid 19 y el confinamiento. Servicio de Publicaciones de la Universidad del País Vasco. Euskal Herriko Unibertsitateko Argitalpen Zerbitzua. Recuperado de https://www.ub.edu/web/ub/ca/menu_eines/noticies/docs/Consecuencias_psicologica s_COVID-19.pdf 
Revista Iberoamericana

de las Ciencias Sociales y

Humanísticas

ISSN: 2395 - 7972

Bautista, N. P. (2011). Proceso de la investigación cualitativa. Epistemología, metodología y aplicaciones. Bogotá, Colombia: Manual Moderno.

Blake, H., Bermingham, F., Johnson, G. and Tabner, A. (2020). Mitigating the psychological impact of Covid-19 on healthcare workers: a digital learning package. Int. J. Environ. Res. Public Health, 17(9). Doi: 10.3390/ijerph17092997

En América, el mayor número de contagios de personal de salud: OPS (1 de septiembre de 2020). La Jornada. Recuperado de https://www.msn.com/es-mx/noticias/mundo/enam\%c3\%a9rica-el-mayor-n\%c3\%bamero-de-contagios-de-personal-de-salud-ops/arBB18DQaq?li=AAggxAT

Gibss, G. (2012). El análisis de datos cualitativos en investigación cualitativa. España: Morata.

Giddens, A. (1991). Modernity and self-identity. Stanford: Stanford University Press.

Henríquez, E. (13 de julio 2020). Chiapas: 732 trabajadores de hospitales contagiados y 41 muertos La Jornada. Recuperado de https://www.jornada.com.mx/ultimas/estados/2020/07/13/chiapas-732-trabajadoresde-hospitales-contagiados-y-41-muertos7002.html\#: :text=A1\%20menos\%20732\%20de\%20los,de\%20la\%20Salud\%20(SNT S)

Hernán, M., Lineros, C. y Ruiz, A. (2020). Cómo adaptar una investigación cualitativa a contextos de confinamiento. Gac Sanit (en prensa). Doi: https://doi.org/10.1016/j.gaceta.2020.06.007

Hernández, M. y García, G. A. (s. f.). Vitalidad mortuoria. Sentido empático de la interacción en los servicios fúnebres (artículo en revisión).

Inchausti, F., MacBeth, A., Hasson-Ohayon, I. and Dimaggio, G. (2020). Psychological intervention and Covid-19: what we know so far and what we can do. Journal of Contemporary Psychotherapy, 1-8. Doi: https://doi.org/10.1007/s10879-020-09460-w

Johnson, M. C., Saletti-Cuesta, L. y Tumas, N. (2020). Emociones, preocupaciones y reflexiones frente a la pandemia del Covid-19 en Argentina. Ciência \& Saúde Coletiva, 25(Supl.1), 2447-2456. Doi: 10.1590/1413-81232020256.1.10472020

Kvale, S. (2011). Las entrevistas en investigación cualitativa. España: Morata.

Lai, J., Ma, S., Wang, Y., Cai, Z., Hu, J., Wei, N., Wu, J., Du, H., Chen, T., Li, R., et al. (2020). Factors associated with mental health outcomes among health care workers 
Revista Iberoamericana

de las Ciencias Sociales y

Humanísticas

ISSN: 2395 - 7972

exposed to coronavirus disease 2019. JAMA Netw. Open, 3(3). Doi: 10.1001/jamanetworkopen.2020.3976

Laurent, E. (2020). El otro que no existe y sus comités científicos. Virtualia, (38), 4-7. Recuperado de http://www.revistavirtualia.com/storage/ediciones/pdf/Urce4NRWGNZinco9LK73v MRekUn7yI9530k0112W.pdf

Lipovetsky, G. (1990). El imperio de lo efímero. Barcelona: Anagrama.

Mamzer, H. (2020). Postmodern society and Covid-19 pandemic: old, new and scary. Society Register, 4(2), 7-18. Doi: 10.14746/sr.2020.4.2.01

Mauss, M. (2017). Otros dones (compilado por Andrés Dapuez) (1. ${ }^{\text {a }}$ ed.). Santiago del Estero, Argentina: Barco Edita.

México es el país con más muertes entre el personal de salud por Covid-19: Amnistía Internacional (3 de septiembre de 2020). Sin Embargo. Recuperado de https://www.msn.com/es-mx/noticias/mexico/m\%c3\%a9xico-es-el-pa\%c3\%ads-conm\%c3\%a1s-muertes-entre-el-personal-de-salud-por-covid-19-amnist\%c3\%adainternacional/ar-BB18Elsl?li=AAggxAT

Nancy, J. L. (2020). Excepción viral. Publicado en Antinomie.it 28 de febrero. En Agamben, G. et al. (2020), Sopa de Wuhan (pp. 29-30). Argentina: Pablo Amadeo Editor. Recuperado de https://lapeste.org/wp-content/uploads/2020/04/Sopa-deWuhan-ASPO.pdf

Organización Mundial de la Salud [OMS] (2020). Preguntas y respuestas sobre la enfermedad por coronavirus (Covid-19). Recuperado de https://www.who.int/es/emergencies/diseases/novel-coronavirus-2019/advice-forpublic/q-a-coronaviruses

Santoro, P. (2020). Coronavirus: la sociedad frente al espejo. En El Colegio de Sonora (comps.), Dossier covid 19: impactos socioculturales de la pandemia (pp. 21-24). México: El Colegio de Sonora. Centro de Estudios de Salud y Sociedad. Recuperado de

https://www.colson.edu.mx/promocion/img/Dossier\%20Covid19_Impactos\%20socio culturales.pdf 
Revista Iberoamericana

de las Ciencias Sociales y Humanísticas

ISSN: $2395-7972$

Secretaría de Salud (31 de marzo de 2020). 098. Medidas de seguridad sanitaria. Secretaría de Salud. Recuperado de: https://www.gob.mx/salud/prensa/098-medidas-deseguridad-sanitaria?idiom=es

Silva, M. L. (2015). El psicoanálisis en los tiempos del miedo Sociedad Peruana de Psicoanálisis. Calibán, Revista Latinoamericano de Psicoanálisis, 13(2), 99-115. Recuperado de http://www.bivipsi.org/wpcontent/uploads/Caliban_Vol13_No2_2015_-esp_p99-115.pdf

Smith, E., Burkle, F., Gebbie, K. Ford, D. and Bensimon, C. (2019). A qualitative study of paramedic duty to treat during disaster response. Disaster Med Public Health Prep., 13(2), 191-196. Doi: 10.1017/dmp.2018.15

Soler, P. (2007). Factores psicosociales explicativos del voluntariado universitario (tesis de doctorado). Universidad de Alicante, Alicante España. Recuperado de https://rua.ua.es/dspace/bitstream/10045/7756/1/tesis_doctoral_patricia_soler.pdf

Solera, C. (11 de mayo de 2020). Paramédicos viven entre la saturación y la soledad. Excélsior. Recuperado de https://www.excelsior.com.mx/nacional/paramedicosviven-entre-la-saturacion-y-la-soledad-atienden-hasta-40-llamados-al-dia

Venegas, P. (8 de mayo de 2020). Confirman el contagio de 4 paramédicos a Covid 19 en Tlalnepantla $\mathrm{El}$ Sol de Toluca. Recuperado de https://www.elsoldetoluca.com.mx/local/confirman-el-contagio-de-4-paramedicos-acovid-19-en-tlalnepantla-5202846.html

Xiang, Y. T., Yang, Y., Li, W., Zhang, L., Zhang, Q., Cheung, T. y Ng, C. H. (2020). Timely mental health care for the 2019 novel coronavirus outbreak is urgently needed. The lancet. Psychiatry, 7(3), 228-229. Doi: https://doi.org/10.1016/S22150366(20)30046-8 
Revista Iberoamericana

de las Ciencias Sociales y

Humanísticas

\begin{tabular}{|c|c|}
\hline Rol de Contribución & Autor (es) \\
\hline Conceptualización & Germán Alejandro García Lara (principal) \\
\hline Metodología & $\begin{array}{l}\text { Germán Alejandro García Lara (principal) Oscar Cruz Pérez } \\
\text { (apoyo) Jesús Ocaña Zúñiga (apoyo) }\end{array}$ \\
\hline Software & NO APLICA \\
\hline Validación & $\begin{array}{l}\text { Germán Alejandro García Lara (principal) Irma Hernández } \\
\text { Solís (igual) }\end{array}$ \\
\hline Análisis Formal & $\begin{array}{l}\text { Germán Alejandro García Lara (principal) Irma Hernández } \\
\text { Solís (apoyo) Soledad Hernández Solís (apoyo) Oscar Cruz } \\
\text { Pérez (apoyo) Jesús Ocaña Zúñiga (apoyo) }\end{array}$ \\
\hline Investigación & $\begin{array}{l}\text { Germán Alejandro García Lara (principal) Irma Hernández } \\
\text { Solís (igual) Soledad Hernández Solís (igual) Oscar Cruz Pérez } \\
\text { (apoyo) Jesús Ocaña Zúñiga (apoyo) }\end{array}$ \\
\hline Recursos & $\begin{array}{l}\text { Germán Alejandro García Lara (principal) Irma Hernández } \\
\text { Solís (igual) Soledad Hernández Solís (igual) Oscar Cruz Pérez } \\
\text { (apoyo) Jesús Ocaña Zúñiga (apoyo) }\end{array}$ \\
\hline Curación de datos & $\begin{array}{l}\text { Germán Alejandro García Lara (principal) Irma Hernández } \\
\text { Solís (igual) Soledad Hernández Solís (apoyo) Oscar Cruz } \\
\text { Pérez (apoyo) Jesús Ocaña Zúñiga (apoyo) }\end{array}$ \\
\hline $\begin{array}{l}\text { Escritura - Preparación del } \\
\text { borrador original }\end{array}$ & $\begin{array}{l}\text { Germán Alejandro García Lara (principal) Soledad Hernández } \\
\text { Solís (igual) }\end{array}$ \\
\hline $\begin{array}{l}\text { Escritura - Revisión y } \\
\text { edición }\end{array}$ & $\begin{array}{l}\text { Germán Alejandro García Lara (principal) Soledad Hernández } \\
\text { Solís (igual) Oscar Cruz Pérez (apoyo) Jesús Ocaña Zúñiga } \\
\text { (apoyo) Irma Hernández Solís (apoyo) }\end{array}$ \\
\hline Visualización & $\begin{array}{l}\text { Germán Alejandro García Lara (principal) Irma Hernández } \\
\text { Solís (apoyo) Soledad Hernández Solís (apoyo) Oscar Cruz } \\
\text { Pérez (apoyo) Jesús Ocaña Zúñiga (apoyo) }\end{array}$ \\
\hline Supervisión & $\begin{array}{l}\text { Germán Alejandro García Lara (principal) Soledad Hernández } \\
\text { Solís (igual) Irma Hernández Solís (apoyo) Oscar Cruz Pérez } \\
\text { (apoyo) Jesús Ocaña Zúñiga (apoyo) }\end{array}$ \\
\hline $\begin{array}{l}\text { Administración de } \\
\text { Proyectos }\end{array}$ & Germán Alejandro García Lara (principal) \\
\hline Adquisición de fondos & Germán Alejandro García Lara (principal) \\
\hline
\end{tabular}

